\title{
Effect of ZnO/Tourmaline on Inhibition of SRB: A Theoretical Account
}

\author{
Meng Gong \\ North China Electric Power University, Beijing 102206, P. R. China \\ dele333@126.com
}

\begin{abstract}
Keywords: Sulfate Reducing Bacteria (SRB); ZnO/Tourmaline ;Density Functional Theory (DFT) Abstract. Potential mechanism of inhibition of Sulfate Reducing Bacteria (SRB) at the presence of $\mathrm{ZnO} /$ Tourmaline was further investigated by Density Functional Theory (DFT) calculation. The structure and electronic states analysis quantitatively and qualitatively dictate the selectively catalytic generation of $\mathrm{OH}$ and $\mathrm{OOH}$ on different $\mathrm{ZnO}$ surface. Results confirms that $\mathrm{OH}^{-0.57}$ on $\mathrm{ZnO}(101)$ and $\mathrm{OOH}^{-0.27}$ on $\mathrm{ZnO}(100)$ is chemically active, which should act as ROS for the inhibition of SRB. Tourmaline showed synergetic effect on the accumulation of $\mathrm{H}_{2} \mathrm{O}$ on $\mathrm{ZnO}$ surface, which will favor the generation reaction of reactive oxygen species (ROS), hence promoting the inhibition of SRB.
\end{abstract}

\section{Introduction}

Sulfate reducing bacteria (SRB) use sulfate or other oxide sulfur compound as oxidizing agent, reducing to sulfide. SRB belong to 9 bacterial phyla and over 200 species ${ }^{[1]}$. SRB are the main reason to cause the microbiologically influenced corrosion by accelerating corrosion rate, inducing stress corrosion and pitting corrosion ${ }^{[2,3]}$. According to statistics of Petrochina in 1997, the financial loss due to corrosion was amount to 0.25 billion Yuan. The sterilization and inhibition of SRB is the main concern in oil field.Many biological approaches to SRB inhibition were employed in previous researches. $\mathrm{SO}_{4}{ }^{2-}$ reduction was inhibited by addition of $\mathrm{NO}^{3-}$ in anoxic paddy soil. Nitrate reducers, and sulfate reducers compet for electron donors ${ }^{[4]}$. $\mathrm{NO}^{2-}$, denitrification products $\mathrm{NO}$ and $\mathrm{N}_{2} \mathrm{O}$ were more competent for inhibition of bacteria than nitrate ${ }^{[5]}$. These methods is aimed to control sulfide emission rely on increasing redox potential. However, all of these methods have a problem with the high cost.Addition of oxidizing chemicals such as $\mathrm{H}_{2} \mathrm{O}_{2}$ or chlorines chemically oxidizes sulfide, thereby decreasing the amount of dissolved sulfide ${ }^{[6]}$. Cerium-doped $\mathrm{TiO}_{2}$ film with bactericidal activity was prepared on 304 stainless steel by a sol-gel process ${ }^{[7]}$. The intrinsic mechanism of inhibiting SNB is not investigated so far.

Herein, the potential mechanism of inhibition of SRB at the presence of the prepared nano $\mathrm{ZnO}$ /Turmaline was theoretically investigated using Density Functional Theory (DFT) calculations. $\mathrm{H}_{2} \mathrm{O}$ interacts to different site of $\mathrm{ZnO}$ related to different reaction paths resulting in the generation of different surface species was discussed and confirmed weather they are ROS for the inhibition of SRB. The synergetic effect of Turnaline for the $\mathrm{ZnO} /$ Turmaline in the aqueous solution system was detected. Such fundamental understanding of the synergetic effect of Turnaline and the selective catalytic generation of ROS on different $\mathrm{ZnO}$ surfaces will contribute to the design and development of high-performance bacterial inhibitors for environmental science, biological sciences, medicine and materials science.

\section{Meterisl and Method}

In reference to the catalytic reaction based on supported cluster models ${ }^{[8,9]}$, DFT and periodic slab models were used to study the interaction between $\mathrm{H}_{2} \mathrm{O}$ on $\mathrm{ZnO}$ surface. All calculations were performed using DFT with the generalized gradient approximation (GGA) and PBE method to realize the exchange correlation energy of the system. All reactants, products, and intermediates were completely optimized. Optimization of the energy, displacement and force convergence were used as a criterion. Convergence valve were $1.0 \times 10^{-5} \mathrm{eV} /$ atom, $5.0 \times 10^{-3} \AA$ and $4.0 \times 10^{-3} \mathrm{eV} / \AA$ respectively. 
A complete linear synchronous transit (LST) and quadratic synchronous (QST) search algorithm was employed to identify the transition state of this dissociation reaction and the transition state that had a unique imaginary frequency ${ }^{[10]}$.

Molecular dynamics (MD) simulation procedures were used to investigate the adsorption of $\mathrm{H}_{2} \mathrm{O}$ on $\mathrm{ZnO}$ surface. In the MD simulation, the conjugate gradient method is used for the minimization. The self-adsorption of $\mathrm{H}_{2} \mathrm{O}$ onto $\mathrm{ZnO}$ surface was minimized under the conditions of constant pressure and constant temperature (NPT) ensembles ${ }^{[11]}$. The simulation protocol, with the time step of 1 fs to integrate Newton's equation of motion and the saving frequency of every $10 \mathrm{ps}$ for the coordinates of the structures, helps to ensure the stability of the simulation process. Nonbonded cut-off of $15.5 \AA$ was applied to truncate the long-range interaction to speed up the computation. The particle-mesh Ewald method (PME) algorithm with cubic-spline interpolation (1 $\AA$ grid width) was applied to calculate electrostatic interactions efficiently ${ }^{[12]}$.

\section{Results and discussion}

\section{Potential mechanism of inhibition of SRB}

As reported, $\mathrm{Zn} 2+$ liberation and reactive oxygen species (ROS) production are thought to be the two potential toxic mechanisms of $\mathrm{ZnO}$, and it is generally accepted that ROS is a major factor in the inhibition of bacteria ${ }^{[13]}$. However, it is lack of qualitative and quantitative research on the type and activity of ROS. Herein, the investigation begins with the interaction between different surfaces of $\mathrm{ZnO}$ under hypoxic environment.

Figure 1 shows the stable structures and the related calculated potential energy profiles for the adasorption of $\mathrm{H}_{2} \mathrm{O}$ on $\mathrm{ZnO}$. The interactions initiate from the optimized physisorption configuration, and then the final state relates to the dissociated adsorption of $\mathrm{H}_{2} \mathrm{O}$ on $\mathrm{ZnO}$. Results of Figure 1a suggests that $\mathrm{H}_{2} \mathrm{O}$ chemically interacts to the bridge site between the $\mathrm{Zn}$ atom and $\mathrm{O}$ atom of $\mathrm{ZnO}(100)$ surface, leading to the generation of $\mathrm{OH}$ group and $\mathrm{H}$ atom, and $\mathrm{H}_{2} \mathrm{O}$ acts as electron accepter in the adsorption system.

Figure $1 \mathrm{~b}$ illustrates the adsorption of $\mathrm{H}_{2} \mathrm{O}$ on the bridge site between two $\mathrm{O}$ atoms of $\mathrm{ZnO}(100)$ surface from the physisorption state to the final state, which is exothermic, and the reaction energy is $-3.868 \mathrm{eV}$. At the physisorption state (reactant) there is no electron transfer and repopulation between $\mathrm{H} 2 \mathrm{O}$ and $\mathrm{ZnO}(100)$ according to the calculation of charge population. However with H2O's approaching to $\mathrm{ZnO}(100), \mathrm{OOH}$ group and $\mathrm{OH}$ group generated at the intermediate state. The charge population on $\mathrm{OOH}$ group and $\mathrm{OH}$ group is -0.520 and -0.590 , respectively. Then with further electronic interaction happen between $\mathrm{ZnO}(100)$ and $\mathrm{OOH}$ group and $\mathrm{OH}$ group, the intermediate changed into the product, which the charge population on $\mathrm{OOH}$ group and $\mathrm{OH}$ group is -0.270 and 0.600, respectively. Comparing Figure 1a with Figure $1 \mathrm{~b}$, we can observe that $\mathrm{H}_{2} \mathrm{O}$ interacts to different site of $\mathrm{ZnO}(100)$ related to different reaction paths resulting in the generation of different surface species.

Figure $1 \mathrm{c}$ depicts the stable adsorption configuration of $\mathrm{H}_{2} \mathrm{O}$ on the long bridge site between $\mathrm{Zn}$ atom and $\mathrm{O}$ atom of $\mathrm{ZnO}(101)$ surface from the physisorption state through the intermediate state to the product. This process has to climb over a small energy barrier of about $0.004 \mathrm{eV}$ at the intermedicate state and then goes into the final state with the release of $0.743 \mathrm{eV}$.

Further, we definitively identified the adsorbed species by analyzing the structure and electronic states. The bond length of the generated $\mathrm{OH}$ groups shown in Figure 1a, b, and c, is $0.947 \AA, 0.944 \AA$, and $0.946 \AA$, respectively, which are shorter than that of the pure hydroxyl radical $(0.961 \AA)$ and the hydroxyl ion $(0.951 \AA)$. The total charge for the generated OH groups shown in Figure 1a, b, and c, is, -0.57 , and -0.57 , respectively, which transfer from $\mathrm{ZnO}$ surface making the spin zero. These generated $\mathrm{OH}$ groups shown in Figure 1a, b, and c can be denoted as $\mathrm{OH}^{-0.60}, \mathrm{OH}^{-0.57}$, and $\mathrm{OH}^{-0.57}$, respectively. We further analyzed the density of state (DOS) and orbit of the generated $\mathrm{OH}^{-0.60}, \mathrm{OH}-0.57, \mathrm{OH}^{-0.57}$, $\mathrm{OOH}^{-0.27}$. Figure 2 depicts the DOS, integrated DOS, highest occupied molecular orbit (HOMO) and lowest unoccupied molecular orbit (LUMO) of $\cdot \mathrm{OH}, \mathrm{OH}^{-}$, and the generated $\mathrm{OH}$ group on $\mathrm{ZnO}(100)$ 
and $\mathrm{ZnO}(101)$, b) DOS and integrated DOS of $\mathrm{H}_{2} \mathrm{O}_{2}$, and the generated $\mathrm{OOH}$ group on $\mathrm{ZnO}(100)$. The DOS of $\mathrm{OH}^{-}$located at around $-4.5 \mathrm{eV}$ and $-0.5 \mathrm{eV}$ with two large peaks. The DOS of $\cdot \mathrm{OH}$ delocalizes at the range of $-4.5 \mathrm{eV}$ to $-2.5 \mathrm{eV}$, and the range of $-1.0 \mathrm{eV}$ to $0.5 \mathrm{eV}$. According to the peack around Fermi energy $(0.0 \mathrm{eV})$, the outer molecular orbit of $\cdot \mathrm{OH}$ is half filled, corresponding to the integrated DOS of $\cdot \mathrm{OH}$ (9 atoms) and $\mathrm{OH}^{-}(10$ atoms), respectively. The delocalization and the half fill of $\cdot \mathrm{OH}$ contributed to the high reaction activity. The DOS of $\mathrm{OH}^{-0.60}$ shown in Figure la move to lower energy while compared to that of $\cdot \mathrm{OH}$ and $\mathrm{OH}-$, which would be less chemically active. The DOS of $\mathrm{OH}^{-0.57}$ shown in Figure 1c is delocalized and half-filled at around Fermi energy, which is very similar to the DOS of $\cdot \mathrm{OH}$. Therefore the $\mathrm{OH}^{-0.57}$ shown in Figure 1c would be high chemically active as $\cdot \mathrm{OH}$ for inhibition of SRB. DOS of $\mathrm{OOH}^{-0.27}$, while compared to that of $\mathrm{H}_{2} \mathrm{O}_{2}$, delocalized from $-15.0 \mathrm{~V}$ to $-11.0 \mathrm{eV}$ and from $-3.0 \mathrm{eV}$ to $0.5 \mathrm{eV}$, the outer bonding-orbit of which is all half-filled. This property will make $\mathrm{OOH}^{-0.27}$ as reactive oxygen species.

$2 \mathrm{p}$-orbit of $\mathrm{O}$ atom contributes to the $\mathrm{HOMO}$ of $\cdot \mathrm{OH}$ and $\mathrm{OH}^{-}$, respectively. However, while anti-bonding orbital $\left(4 \sigma^{*}\right)$ of $\mathrm{OH}^{-}$contributes to the LUMO, the unfilled $2 \mathrm{p}$-orbit of $\mathrm{O}$ atom contributes to the HOMO of $\cdot \mathrm{OH}$. For $\mathrm{OH}^{-0.60}$ shown in Figure 1a, 2p-orbit of $\mathrm{O}$ atom contributes to the HOMO and 2p-orbit of $\mathrm{O}$ atom together with part of $\mathrm{O}-\mathrm{H}$ bond contributes to the LUMO. For $\mathrm{OH}^{-0.57}$ and $\mathrm{OOH}^{-0.27}$ shown in Figure $1 \mathrm{~b}, 2 \mathrm{p}$-orbit of $\mathrm{O}$ atom contributes to the $\mathrm{HOMO}$ of $\mathrm{OH}^{-0.57}$ and the anti-bonding orbital contributes to the LUMO of $\mathrm{OH}^{-0.57}, 2 \mathrm{p}$-orbits of the two $\mathrm{O}$ atoms contribute to both HOMO and LUMO of $\mathrm{OOH}^{-0.27}$, which corresponds to the half-filled DOS and the spin analysis.

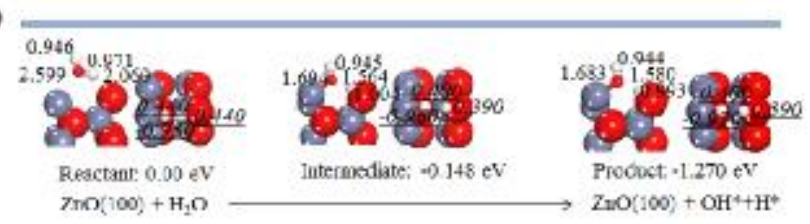

b)

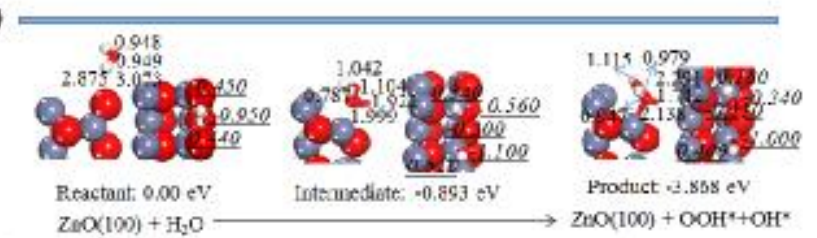

c)

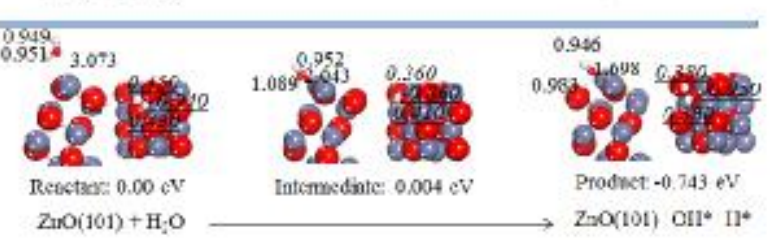

Figure 1 Structures and the related calculated potential energy profiles for the adsorption of water molecule on $\mathrm{ZnO}$. Distances are given in units of $\AA$. Charges of the atoms are underlined.
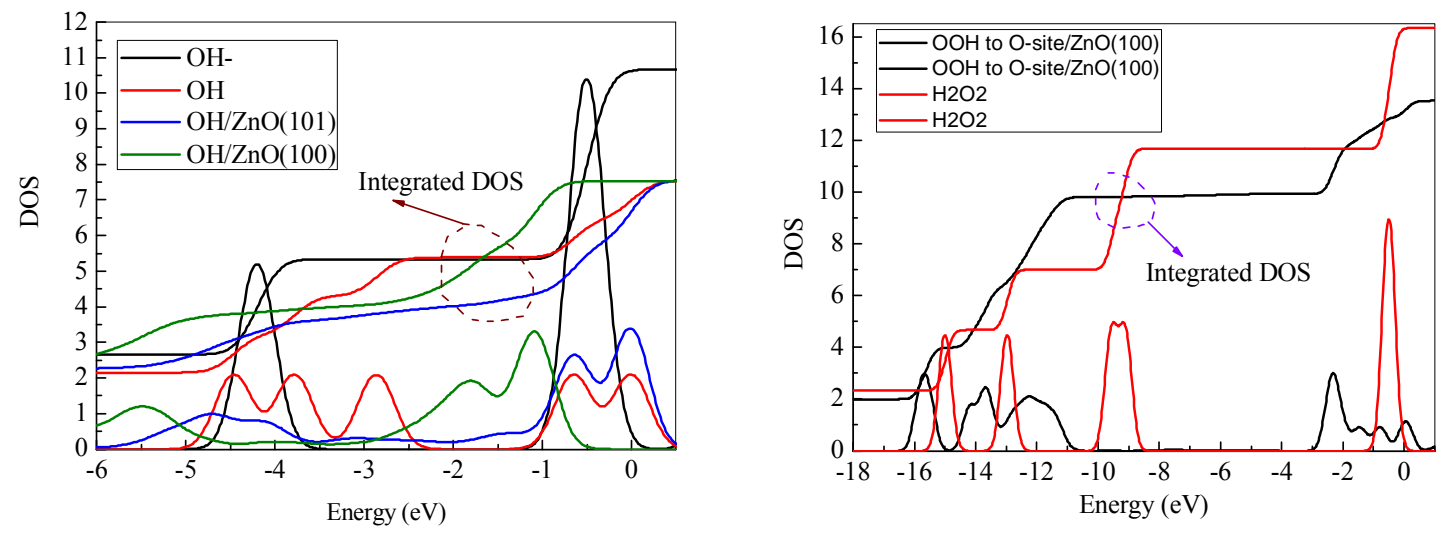

Figure 2 a) DOS and integrated DOS of $\cdot \mathrm{OH}, \mathrm{OH}^{-}, \mathrm{OH}^{-0.60}, \mathrm{OH}^{-0.57}$, and $\mathrm{OH}^{-0.57}$. b) DOS and integrated $\mathrm{DOS}$ of $\mathrm{H}_{2} \mathrm{O}_{2}$, and $\mathrm{OOH}^{-0.27}$. 


\section{Synergetic effect of Tourmaline on $\mathrm{ZnO}$}

Figure 3 lists the density field for $\mathrm{H}_{2} \mathrm{O}$ over $\mathrm{ZnO}$. The red output field represents a small density distribution of $\mathrm{H}_{2} \mathrm{O}$ over $\mathrm{ZnO}(100)$ and $\mathrm{ZnO}(100) /$ Turnaline lattice framework while the blue output field represents a high density distribution of $\mathrm{H}_{2} \mathrm{O}$ over $\mathrm{ZnO}(100)$ and $\mathrm{ZnO}(100) /$ Turnaline lattice framework. That more $\mathrm{H}_{2} \mathrm{O}$ molecules are adsorbed more closely to surface of $\mathrm{ZnO}(100)$ /Turnaline than to the surface of $\mathrm{ZnO}(100)$, implying a certain synergetic effect of Turnaline for the adsorption $\mathrm{H}_{2} \mathrm{O}$ to $\mathrm{ZnO}$ surface.

The adsorption isotherms of $\mathrm{H}_{2} \mathrm{O}$ on $\mathrm{ZnO}$ at room temperature are shown in Figure $3 \mathrm{~b}$, which displays the adsorption of $\mathrm{H}_{2} \mathrm{O}$ molecules per $\mathrm{nm} 2$ at each fugacity. The total fugacity reports the sum of the sorbate component fugacities in $\mathrm{kPa}$. That the adsorption isotherms of $\mathrm{H}_{2} \mathrm{O}$ belong to Langmuir-type; i.e., the adsorption capacities initially increase quickly and almost reach the maximum value at around $2000 \mathrm{kPa}$. In Figure 3, the adsorption capacity and the slope of the adsorption curve before reaching the maximum adsorption capacity for $\mathrm{ZnO}(100) /$ Turnaline is large than those for $\mathrm{ZnO}(100)$, suggesting that Turnaline favour the adsorption of $\mathrm{H}_{2} \mathrm{O}$ on $\mathrm{ZnO}$ surface.

The adsorption energy distribution for individual isotherms can be further calculated from the general adsorption integral equation, given by:

$$
\Gamma_{t}(p, T)=\int \Gamma(p, T, U) f(U) d U
$$

where $\Gamma \mathrm{t}$ denotes the overall adsorption isotherm, $\Gamma$ the local adsorption isotherm on surface having an interaction energy $U$, and $f(U)$ is the energy distribution function to be obtained [37].

According to the adsorption isotherm of $\mathrm{H}_{2} \mathrm{O}$ on $\mathrm{ZnO}$ above, the local adsorption isotherm models Langmuir [38] can be applied. While the maximum adsorption potential energy for the adsorption on $\mathrm{ZnO}(100) /$ Turnaline is located around $-0.54 \mathrm{eV}$, the maximum adsorption potential energy for the adsorption on $\mathrm{ZnO}(100)$ is at around $-0.48 \mathrm{eV}$ (Figure 3 black line). Such effect is possibly related to the synergetic effect of Turnaline, which can usually promote the accumulation of $\mathrm{H}_{2} \mathrm{O}$ on the surface of $\mathrm{ZnO}$, hence favoring the generation of ROS to inhibit SRB.
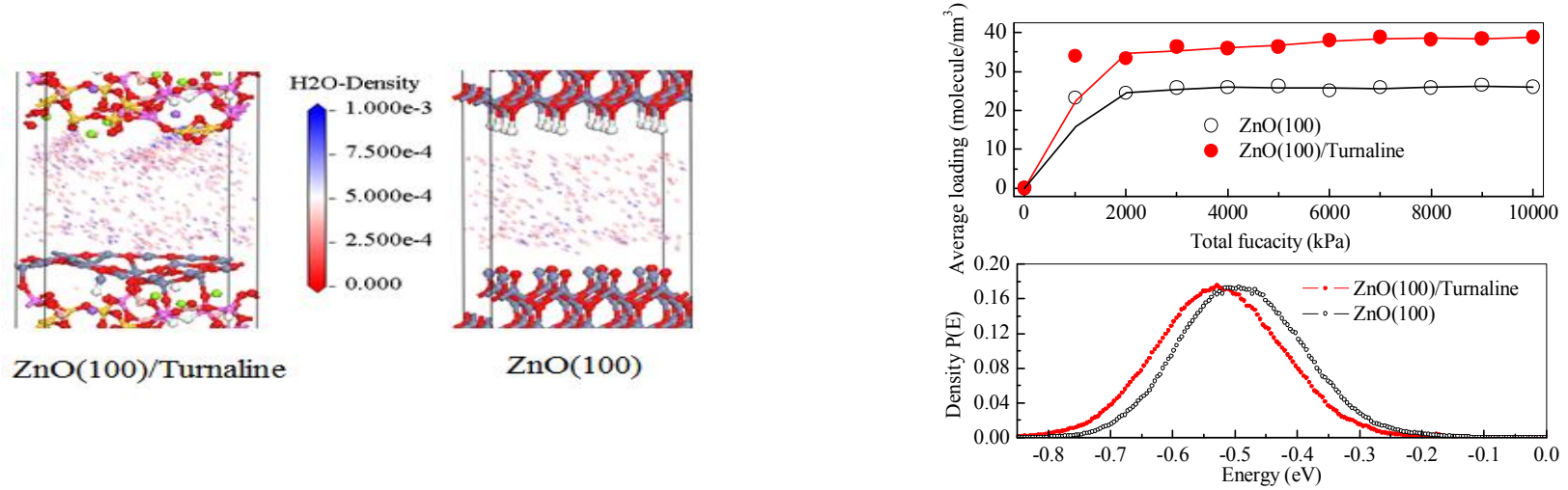

Figure 3 Density field for $\mathrm{H}_{2} \mathrm{O}$ over $\mathrm{ZnO}$, b) adsorption isotherms and energy distribution functions $\mathrm{P}(\mathrm{E})$ of $\mathrm{H}_{2} \mathrm{O}$ over $\mathrm{ZnO}$ atom room temperature

\section{Conclusions}

The potential mechanism of inhibition of $\mathrm{SRB}$ at the presence of $\mathrm{ZnO}$ /Turmaline were investigated qualitatively and quantitatively research using DFT calculations. $\mathrm{H}_{2} \mathrm{O}$ interacts to different site of $\mathrm{ZnO}$ related to different reaction paths resulting in the generation of different surface species. The generated $\mathrm{OH}$ groups and $\mathrm{OOH}$ group on $\mathrm{ZnO}$ surfaces can be denoted as $\mathrm{OH}^{-0.60}, \mathrm{OH}^{-0.57}, \mathrm{OH}^{-0.57}$, and $\mathrm{OOH}^{-0.27}$, respectively. We further analyzed the density of state (DOS) and orbit of the generated $\mathrm{OH}^{-0.60}, \mathrm{OH}^{-0.57}$, $\mathrm{OH}^{-0.57}, \mathrm{OOH}^{-0.27}$. The structure and electronic states analysis quantitatively and qualitatively dictate the selectively catalytic generation of $\mathrm{OH}$ and $\mathrm{OOH}$ on different $\mathrm{ZnO}$ surface. Results confirms that $\mathrm{OH}^{-0.57}$ on $\mathrm{ZnO}(101)$ and $\mathrm{OOH}^{-0.27}$ on $\mathrm{ZnO}(100)$ is chemically active, which should as $\mathrm{ROS}$ for the inhibition of SRB. Further Turnaline promotes the interaction and accumulation of $\mathrm{H}_{2} \mathrm{O}$ on the surface 
of $\mathrm{ZnO}$, hence favoring the generation of ROS to inhibit SRB. Fundamental understanding of the synergetic effect of Turnaline and the selective catalytic generation of ROS on different $\mathrm{ZnO}$ surfaces will contribute to the design and development of high-performance bacterial inhibitors for environmental science, biological sciences, medicine and materials science.

\section{Acknowledgement}

The authors wish to thank the Fundamental Research Funds for the 111 Project (B12034).

\section{References}

[1] D. Starosvetsky, J. Starosvetsky, R. Armon, Y. Ein-Eli. A peculiar cathodic process during iron and steel corrosion in sulfate reducing bacteria (SRB) media[J]. Corrosion Science, 2010,52:1536 1540

[2] [3] Sadegh Sh. Abedi, Ail .Abdolmaleki, N. Adibi, Failure analysis of SCC and SRB induced cracking of a transmission oil products pipeline. Engineering Failure Analysis, vol. 14, pp 250-261, 2007.

[4] Achtnich C, Bak F, Conrad R. Competition for electron donors among nitrate reducers, ferric iron reducers, sulfate reducers, and methanogens in anoxic paddy soil. Biol Fertility Soils 1995;19:65-72.

[5] Zumft W G. The biological role of nitric oxide in bacteria[J]. Arch. Microbiol., 1993,160:253-264.

[6] Setareh M, Javaherdashti R. Assessment and control of MIC in a sugar cane factory[ J] .Materials and Corrosion, 2003, 54: 259 263.

[7] Hongfen Wang, Zhiqi Wang Haixia Hong Yansheng Yin. Preparation of cerium-doped TiO2 film on 304 stainless steel and its bactericidal effect in the presence of sulfate-reducing bacteria (SRB) [J]Materials Chemistry and Physics,2010,124:791 794

[8] W.Qin, X. Li, Phys. J. Chem. C 114 (2010) 19009.

[9] W. Qin, X. Li, J. Chem. Phys. Lett. 502 (2011) 96.

[10] Y. Li, L. Tang, J. Li, Electrochem. Commun. 11 (2009) 846.

[11] J.C. Phillips, R. Braun, W. Wang, J. Gumbart, E. Tajkhorshid, E. Villa, C. Chipot, R. D. Skeel, L. Kale, K. Schulten. J. Comput. Chem. 26 (2005) 1781.

[12] T. Darden, D. York, L. Pedersen. J. Chem. Phys. 98 (1993) 10089.

[13] X. R. Liu, J. H. Li, Y. Zhang, Y. S. Ge, F. F. Tian, J. Dai, F. L. Jiang and Y. Liu, J. Membr. Biol., 2011, 244, 105-112 